\title{
Notes on Operations One Title, Hundreds of Volumes, Thousands of Documents Collaborating to Describe the Congressional Serial Set
}

\author{
Suzanne M. Ward, Patricia A. Glasson, \\ and Randall F. Roeder
}

As part of its participation in the Google Books government documents scanning project, the Purdue University Libraries agreed to contribute volumes of the Congressional Serial Set (CSS). Realizing that the results would be far more useful if the individual documents within this title were cataloged separately, librarians developed procedures to create brief records and began cataloging CSS documents from the 1890s. The University of Iowa became a partner in this collaborative pilot project, and its cataloging staff used the Purdue template and procedures to create records from the CSS for individual documents from two years in the 1890s. Purdue staff used those records to barcode their own corresponding CSS documents before sending those volumes to Google for scanning. Staff subsequently loaded the records into WorldCat to improve discoverability for scholars. The result of the collaborative cataloging effort was the ability to prepare CSS volumes for scanning quickly and efficiently.

Suzanne M. Ward (ward@purdue.edu) is Head, Collection Management, Purdue University Libraries. Patricia A. Glasson (pglasson@purdue.edu) is Head, Metadata Services at Purdue University Libraries. Randall F. Roeder (randy-roeder@uiowa.edu) is Head, Cataloging-Metadata Department, University of lowa Libraries.

Submitted March 4, 2014; returned to authors for minor revision May 29, 2014; revision submitted July 3, 2014; accepted for publication August 8, 2014.
T 1817, construction began on the Erie Canal. Mississippi became a state. Coffee was first planted in Hawaii. Baltimore became the first city in the United States to be lit by gas street lamps. And the publication we now know as the Congressional Serial Set (CSS) began.

Congress and the executive branch had been issuing documents since 1789, but in our nation's early years these publications were neither numbered nor issued regularly in serial collections. ${ }^{1}$ They have since been collected into the American State Papers. ${ }^{2}$

Beginning with the Fifteenth Congress (1817), however, documents issued by Congress and, for the next hundred years, many executive documents as well, were systematically numbered and gathered into a series called by a variety of names over time, but which we now know as the CSS. The CSS contains documents ranging in length from half a page to several volumes. It includes some internal serial titles. It covers a huge variety of topics that interested Congress and the White House over a time span of nearly 200 years. The following are a few examples of these documents:

- In Favor of Reducing and Regulating the Duties on Teas (1828)

- Report from the Secretary of War in Compliance with a Resolution of the Senate, in Reference to the Defense of the Frontier of Maine (1838) 
- Report of the Committee on Resolution of Legislature of Indiana on the Subject of the Wabash and Erie Canal Land Claim (1840)

- Resolutions of Legislature of California in Favor of the Overland Mail and Pony Express (1862)

- Petition of Citizens of the Des Moines Valley, Iowa, Praying Protection in their Rights and the Preservation to Them of Their Homes on the Odd-Numbered Sections of Land in Said Valley (1871)

- Resolution of Inquiry Relative to Analysis of Beer (1888)

- "Titanic" Disaster: Hearing before a Subcommittee of the Committee on Commerce United States Senate (1912)

- Limiting Production of Opium to Amount Required for Medicinal and Scientific Purposes (1944)

- Black Americans in Congress, 1870-2007 (2008)

Rodney A. Ross wrote that "the Serial Set is an invaluable source of information not only on Congress and the entire federal government, but on every conceivable subject for which the federal government has had an interest."3 From recognition of the nation's famous citizens to petitions from "ordinary folks" (the 1871 homeowners from the Des Moines Valley, above), the CSS records items of historical, political, social, and economic interest for nearly two centuries of our country's history. From paper through microform to CD-ROM and now the Internet, these documents form an unparalleled look at our history from both macro and micro perspectives. They are a wealth of primary historical records that can excite researchers from the high school level onwards. For more information about the CSS as a publication, consult Morehead's Introduction to United States Government Information Sources. ${ }^{4}$

\section{Discoverability and Access}

Identifying individual documents of potential interest to a student, historian, or other researcher often proves daunting. The Congressional Serial Set, as its name suggests, is cataloged as a serial. It consists of thousands of volumes, many of which contain anywhere from dozens to several hundred individual documents.

There are a number of printed finding aids available to navigate this resource, but even before the digital age, researchers found these cumbersome to use. Ross remarked that "for a century and one-half the confusing format and poor quality of Serial Set indexes hindered scholars." In 1885, the Government Printing Office (GPO) issued Poore's A Descriptive Catalogue of the Government Publications of the United States, September 5, 1774-March 4, 1881. ${ }^{6}$ Poore's publication was followed by Tables of and Annotated
Index to the Congressional Series of the United States Public Documents (1902). ${ }^{7}$ Next came Ames's Comprehensive Index to the Publications of the United States Government, 1881-1893 in 1905..$^{8}$ The year 1911 saw the publication of Checklist of United States Public Documents, 1789-1909. ${ }^{9}$ The twenty-five-volume Catalogue of the Public Documents of the United States appeared between 1896 and 1945, covering 1896 to $1940 .{ }^{10}$ Some of these publications indexed CSS documents plus other US government publications.

Librarians and researchers responded to the fact that these finding aids were complicated to use by writing articles such as "Beginner's Guide to Indexes to the Nineteenth Century U.S. Serial Set" and "The 1909 Checklist Revisited." Johnson's Guide to American Indian Documents in the Congressional Serial Set, 1817-1899 (1977). ${ }^{12}$

Ross praised the publication of the CIS US Serial Set Index, 1789-1969 published between 1975 and $1998 .{ }^{13}$ This large multivolume work is divided into twelve chronological parts, covering both the American State Papers and the CSS. There is also a subject index, an index of names and organizations, an index by bill numbers, and a carto-bibliography of maps. When researchers find relevant entries after using these finding aids, they must still locate the documents in the CSS volumes. Contemporary researchers shudder at this two-step process. They are accustomed to access being a click beyond discovery. For researchers and the general public who may not have easy access to an institution holding the physical CSS volumes, getting their hands on an actual document presents a challenge.

Several commercial publishers have digitized the CSS or are in the process of doing so. For scholars affiliated with organizations able to pay for access to these databases, the discoverability and access issues have been solved. However, for the average citizen and researchers at smaller organizations, discoverability and access, particularly for titles published before digitization was common, are still nearly as difficult as they were prior to the Internet.

There have been efforts to address this difficulty. There are some files of scanned content pages of the documents issued during selected Congresses available on the web, but as the older ones lack optical character recognition and are thus not machine searchable, one must still visually peruse each one to choose titles of interest. ${ }^{14}$ The same is true of the pre-1923 finding aids mentioned above, most of which have been digitized and are available as full text in Google Books (books.google.com) or the HathiTrust Digital Library (www. hathitrust.org).

Some non-digital individual titles have been digitized, mostly those that are lengthier or more important than others. For example, the 1912 Titanic disaster hearings total 1,163 pages. ${ }^{15}$ Although this document is included in the $C S S$, there are also several individual records for it in 
OCLC's WorldCat (worldcat.org). The document has been scanned and is available on the web through Google Books and HathiTrust, findable by searching title keywords. Pocket Books issued a reprint in $1998 .{ }^{16}$ This edition is accompanied by a four-cassette dramatization of abridged survivor eyewitness accounts gleaned from this government publication and read by "stars of stage and screen." ${ }^{.17}$ While the high level of public interest in this topic motivated the multiple ways in which this particular report is readily available, the vast majority of CSS titles have not received this treatment.

Searching Google Books or HathiTrust reveals a handful of full-text CSS documents individually scanned and discoverable through the words in their titles. These sites include other instances of CSS records, but most of these are for volumes scanned in their entirety, some of them containing over two hundred separate documents per volume. The documents are not arranged in any kind of subject order. For instance, a 1905 report on "Methods and costs of gravel and placer mining in Alaska" follows "Experiments on steel-concrete pipes on a working scale"; at least these two House reports were issued by the same agency. Finding known titles may be easier if they appear as separate records rather than as one of many in an entire scanned CSS volume. Individual records in WorldCat also improve discoverability, but here, too, titles are lacking for many individual CSS documents from the more distant past. For example, during the project described below, library staff found that nearly every CSS document issued in the 1890s with the word "Kansas" in the title was represented in a WorldCat record, apparently the result of an earlier cataloging effort in that state, but very few other titles from this decade already had individual bibliographic entries. Until now, there has been no consistent, reliable effort to make the wealth of information in these documents easily available in a digital format for both researchers and the general public.

\section{Purdue University Libraries and the Google Government Documents Project}

In 2011, the Purdue University Libraries joined a consortial effort to supply material to Google for the Google Books digitization project. Specifically, Purdue entered the part of the project that supplied US federal documents for digitization. These documents were supplied for destructive scanning, meaning that to facilitate the highly efficient sheet-fed digitization at the Google scanning center, the documents were removed from their bindings and run through a highspeed scanner. Any government documents sent to Google took a one-way trip. A number of other libraries in the consortium, the Committee on Institutional Cooperation (CIC; www.cic.net), were already participating in the government documents scanning project.
Purdue sent Google an extract from the local catalog containing US government documents. Google staff selected the titles that they wanted from Purdue and created a pick list of the locally held government documents. Purdue librarians reviewed the pick list to remove titles that Purdue was unwilling to send for destructive scanning, in particular documents from agencies that Purdue had promised to keep as part of a statewide government documents light archives agreement. The Purdue University Libraries were willing to send their Congressional Serial Set volumes for destructive scanning, something that other consortial partners had declined to do. Purdue's holdings for print CSS volumes began with the Twenty-Second Congress (1831-33).

As local planning for the overall government documents project continued, Purdue librarians realized that they had a unique opportunity to contribute to scholarship by preparing the CSS volumes for scanning not as entire volumes but as individual documents. By doing so, individual records for each individual CSS document could be created rather than single records for each multidocument volume. Discoverability would increase exponentially with document-level cataloging coupled with the online access as the scanned documents entered Google Books and, shortly thereafter, HathiTrust. This decision involved barcoding every single document inside a volume and providing a brief bibliographic record for each of those documents. The document-level bibliographic record would follow each document through scanning and into Google Books and HathiTrust. Those records, identifying the individual titles and the unique CSS document numbers for each, would also be added to OCLC's WorldCat to provide another point of discoverability.

The CSS volumes had previously been boxed and moved to one of Purdue's storage facilities. The staff who would be handling the cataloging portion of the project asked that a sample box be sent to their office. The box that arrived contained volumes from the Fifty-Second Congress (1891-93). Purdue's catalog librarians discovered almost immediately that "providing a brief bibliographic record" meant creating a brief bibliographic record for almost every document, since there were few existing individual records for these documents in OCLC's WorldCat.

\section{Cataloging Workflow}

In May 2011, Purdue University Libraries cataloging staff acknowledged that most of the records for the 1890s CSS documents would require original cataloging. They discussed possible workflows for preparing these records for the Google government document project. Full-scale cataloging for thousands of documents would not be possible. The catalogers looked at the controlled vocabulary for the various series and at corporate entities involved. Their initial 
idea was that preparing separate templates with controlled vocabulary terms already correctly formatted would reduce the need for redundant data entry and for checking authority files.

This plan might have worked if there had been more time and resources to hire and train catalogers, but the Google government documents project deadlines had been set before Purdue agreed to the destructive scanning of the CSS volumes. Cataloging more than one hundred years of CSS documents could not possibly be completed within the main project timeframe. Purdue staff resources for cataloging/metadata included one professional cataloger and three staff catalogers. With processing new materials being the top priority for the unit, there was no guarantee that sufficient staff time could be consistently devoted to the CSS project. The best option for making the project operational quickly was to hire student assistants. Even this solution was a daunting task because procedures needed to be established and documented before students could be hired.

As the catalogers tested the workflow, it became clear that the process was complex. There were too many controlled vocabulary terms in too many different combinations, resulting in too many templates with complicated instructions for choosing the best one for each CSS document. Trained catalogers could have relied upon their background knowledge and experience to make informed choices, but it would be impractical to train student workers to this level.

The cataloging supervisor abandoned the original cataloging templates for a master template that was flexible enough to encompass many alternatives. The intention was to provide a basic transcription of each document title in a brief MARC record. It should also be possible to identify the controlled vocabulary needed to enhance each record, should the opportunity present itself. By June 2011, the template was established; catalogers worked through a few samples, developed basic instructions, and hired the project's first student worker. The supervisor hired a second student in July; procedures and documentation had been firmed up, and subsequent hires experienced a more traditional training process that focused on entering data as consistently as possible while including significant elements such as the names, dates, and numbers associated with each document.

Before data entry began, each document was barcoded and its first page marked with a small sticky note so that it could be quickly located within the volume. Staff searched OCLC for each document; if an existing record was found, it was imported and the OCLC number written on the sticky note. Staff corrected any obvious errors in existing records, but did no other editing. Documents that were already cataloged skipped the data entry step. If there was no OCLC record, student workers accessed the template and edited it as needed or copied an existing record and edited it to match the document in hand (see appendix 1). After data entry, staff performed a quality check to ensure that barcodes were correctly linked with corresponding records and that the data entry was accurate. Staff scanned barcodes into a spreadsheet for record keeping and statistical purposes, as required by the overall Google project procedures.

Some CSS volumes contained hundreds of individual documents, others just one or two, so the time needed to complete a volume varied. There was a lot of excitement as the first completed volumes began to accumulate on a book truck, but it was September 2011 before that first book truck was full and taken to the centralized area where volumes were prepared for shipment to Google. By then the CSS cataloging project was running smoothly.

Purdue's participation in the Google government documents project ended in October 2011 with a final shipment. Cataloging staff had time to complete only a few dozen CSS volumes. The project manager began conversations with Google staff about the possibility of sending occasional smaller shipments of CSS volumes for digitization.

Appendix 2 provides a sample record of a CSS document with full cataloging; it was created by another OCLC member library and provides all the details expected for detailed records. Appendix 3 shows an example of a brief record created by a Purdue cataloger for the CSS project. These were developed to provide essential information about each document and to facilitate moving the project forward quickly by creating many short records rather than a few detailed ones. The brief records were added to OCLC without enhancements.

\section{The University of lowa Library as a Cataloging Partner}

As work neared completion on the Fifty-Second Congress, it was clear that the project was far too large for a single institution to complete in a reasonable timeframe while working on a part-time basis. Purdue librarians realized that other libraries might not be willing to barcode their CSS volumes or to send them for destructive scanning. A possible solution was to interest partners in the descriptive portion of the project. Working from local volumes of the CSS, staff at a partner library could describe the documents and share the records with Purdue. Purdue staff could then barcode their own corresponding volumes while matching them to the partner's records.

The librarian who managed the Purdue Google government document project described the CSS project to colleagues on the CIC Technical Services Directors group and asked if any of the other libraries would be willing to pilot the concept of collaborative cataloging for the CSS project. Librarians from the University of Iowa agreed to catalog one Congress. Since the Purdue staff were working forward in time from the Fifty-Second Congress, Iowa was asked to catalog the Fifty-First Congress (1889-91). This agreement 
was followed by several conference calls between key staff at both institutions to share documentation, work out details, and answer questions.

The University of Iowa Libraries have participated in the Federal Depository Library Program since 1884 and were awarded regional depository status in 1963. Because of long affiliation with the depository program, the libraries maintain a comprehensive collection of the paper volumes of the CSS. Responsibility for the bibliographic control of the depository collection has resided with the libraries' Cataloging-Metadata Department (C-MD) since 2004.

The Cataloging-Metadata Department at the University of Iowa Libraries consists of six cataloging librarians and twelve library assistants. The government documents library assistant within the department has primary responsibility for the bibliographic control of newly acquired United States federal documents and serves as gatekeeper for the libraries' ongoing effort to convert an estimated 250,000 paper records to machine-readable form. The government documents retrospective cataloging project, an often-postponed effort with a history of fits and starts, became a priority in 2009 when additional staff time was devoted to the effort.

Within the C-MD, the serials cataloging workgroupone librarian and five library assistants - has had the responsibility for the retrospective cataloging of federal documents added to its charge. Once exclusively responsible for creating and maintaining bibliographic, holdings, and item records for the libraries' serials collection, the group has assumed new duties as batch-loaded MARC records for electronic journals have become the norm. Most of the group members are comfortable working with monographic records, and some have proofread crowd-sourced data or edited images for digitization projects. The workgroup's familiarity with federal documents, its flexibility, and its comfort with both monographic and serials records made it the logical choice for participation in the CSS pilot.

The head of the Cataloging-Metadata Department made the decision to participate in the CSS cataloging pilot after consultation with the libraries' federal documents coordinator and the associate university librarian for information technology (the Cataloging-Metadata Department is part of the libraries' information technology operation). A number of considerations were taken into account. Perhaps the biggest obstacle to the libraries' participation in the project was its existing access to the full-text resource through a commercial vendor. The creation of MARC catalog records would have little immediate impact on the ability of the university community to access the resource since the full text of the CSS was already available through the discovery layer interface. A second negative consideration involved the scale of the project as a whole, a reality that forced the question of whether a successful pilot would lead to a feasible project. A positive was the realization that a completed project would expose the CSS through WorldCat to researchers who previously could not access the costly version offered by commercial vendors. The irony inherent of charges for access to the digital version of a hard copy resource freely available within the depository library system was not lost on participants in the discussion. The greater availability of the information to the general public was in line with the libraries' role as a federal depository and the leadership responsibilities implicit in its regional status. Participation in the pilot would also add to the resources made available to the CIC component of Google Book Project and, by extension, to the HathiTrust Digital Library.

The decision was simplified by the existence of the ongoing federal documents retrospective conversion project. Although there was no plan to create analytical records for the CSS, the process of repurposing conversion project staff was expected to be relatively straightforward. No change in project leadership or staffing would be required, training would be minimal, and the impact of the pilot on the workgroup's other responsibilities would also be minimal since those hours were already committed to work with federal documents. Save for some additional hours spent in workflow design and some unanticipated experimentation with a handheld scanner, the assumption of an easy transition proved accurate.

After the decision to participate was made, the supervisor of the preexisting retrospective conversion effort was appointed project manager. An introductory conference call with staff at Purdue confirmed that neither the repurposing of existing C-MD staff nor the department's wish to use the Connexion Client (OCLC's software for cataloging) for the task were barriers to participation. The project was expected to last approximately four months. The C-MD would target the Fifty-First Congress and, except for required Superintendent of Documents (SuDoc) numbers, the bibliographic records created would be at the minimal level. The department would deliver a spreadsheet with a list of OCLC numbers for the records. The respective project managers would handle further communication between sites. Except for meeting these minimal requirements, the CatalogingMetadata Department was free to conduct the project as it saw fit. It was an ideal situation for a pilot participant-one that encouraged experimentation and allowed for local autonomy.

The print volumes of the CSS were retrieved from storage. Staff at Iowa used a preexisting retrospective conversion workflow, utilizing OCLC's Connexion client for copy editing and creating new records and then exporting the results to its integrated library system (ILS). Save for minor differences in template style, the end result was the same as with the Purdue model-a quick, minimal level record suitable for the Google government documents project. Unlike Purdue, the University of Iowa retained its volumes of the 
CSS, a situation which forced consideration of the thousands of brief analytical records created for the project. There was no question that they would be retained and available in the ILS, but much consideration was given to the advisability of creating holdings and item records for them. The project manager decided to attach a volume-level holdings record to each analytic but to forego the effort involved in linking each analytic to its base volume. There seemed little reason to create item records.

Iowa's part in the collaboration was straightforward. As a result of Purdue's work to eliminate the snags involved in developing the process, it was also very efficient. Once underway, procedures were straightforward and there was little need for more than occasional communication between the two institutions. The only glitch in the operation occurred when Iowa staff, not realizing that the information would be unavailable to Purdue, used the OCLC local call number field (099) to record SuDoc numbers. Since only about one hundred records had been created before this problem was discovered, the situation was easily remedied.

\section{Project Outcome}

The University of Iowa cataloging staff completed record creation for CSS documents from the Fifty-First Congress by March 2012 as anticipated. Since they did their editing and record creation using the OCLC Connexion client, it was easy for them to send Purdue staff a list of OCLC numbers for the records they handled. Purdue staff pulled their corresponding CSS volumes from storage, barcoded each document, and imported the Iowa-created OCLC records. The volumes went to Google for destructive scanning in the next shipment. Staff at both institutions agreed that the process worked well and that a collaborative cataloging project on this scale was feasible. See appendix 4 for an example of one of the records from this project in HathiTrust. Project statistics can be found in appendix 5 .

Despite the positive outcome of the collaborative cataloging pilot project, no other CIC library volunteered to contribute the resources necessary to participate in expanding the pilot into full production. Iowa was unable to commit the resources to continue the project as the sole collaborating partner. The librarian who managed the Google Books government document project for Purdue felt that providing brief document-level cataloging records for the scholarly community at large was an important contribution towards making interesting documents about our country's past discoverable through WorldCat. In the first half of 2012, Purdue staff continued to work forward from the Fifty-Second Congress, creating brief document-level records and preparing CSS volumes for the Google government documents project. However, the library administration decided that other projects, such as the implementation of a discovery layer and the transition to a new integrated library system, took priority for the cataloging staff's attention. With no additional consortial support, the Purdue University Libraries could not handle the entire project alone. The staff completed barcoding and creating brief records for all the CSS volumes for the decade of the 1890s (Fifty-First through Fifty-Fifth Congresses), sent them to Google for scanning, and uploaded the records to WorldCat.

While it is disappointing that other priorities prevented the project from continuing, an important outcome from the effort is proof that collaborative retrospective cataloging on a large scale is feasible, given sufficient interest and resources. If one institution is willing to lead the effort by testing workflow, preparing instructions, and generally coordinating the work, participation by others can be easy. The authors hope that the wealth of information contained in the thousands of individual documents in the Congressional Serial Set will eventually be readily discoverable and available to students and researchers through WorldCat.

\section{References}

1. Anne Morris Boyd, United States Government Publications, 3rd ed., rev. by Rae Elizabeth Rips (New York: H. W. Wilson, 1949), 28.

2. Martin P. Claussen, "Revisiting America’s State Papers, 17891861: A Clinical Examination and Prognosis," American Archivist 36, no. 4 (1973): 523-36.

3. Rodney A. Ross, "Using the U.S. Congressional Serial Set for the Study of Western History," Western Historical Quarterly 25, no. 2 (1994): 212-13.

4. Joe Morehead, Introduction to United States Government Information Sources, 6th ed. (Englewood, CO: Libraries Unlimited, 1999), 146-57.

5. Ross, "Using the U.S. Congressional Serial Set," 208.

6. Benjamin Perley Poore, A Descriptive Catalogue of the Government Publications of the United States, September 5, 1774-March 4, 1881 (Washington, DC: Government Printing Office, 1885).

7. United States Superintendent of Documents, Tables of and Annotated Index to the Congressional Series of the United States Public Documents (Washington, DC: Government Printing Office, 1902).

8. John G. Ames, Comprehensive Index to the Publications of the United States Government, 1881-1893 (Washington, DC: Government Printing Office, 1905).

9. Mary A. Hartwell, Checklist of United States Public Documents, 1789-1909 (Washington, DC: Government Printing Office, 1911).

10. United States Superintendent of Documents, Catalogue of the Public Documents of Congress and of All Departments of the Government of the United States (Washington, DC: Government Printing Office, 1896-1945). 
11. Mary Larsgaard, "Beginner's Guide to Indexes to the Nineteenth Century U.S. Serial Set," Government Publications Review 2, no. 4 (1975): 303-11; Elizabeth A. McBride, "The 1909 Checklist Revisited," Government Publications Review 12, no. 5 (1985): 421-25.

12. Steven L. Johnson, Guide to American Indian Documents in the Congressional Serial Set, 1817-1899: A Project of the Institute for the Development of Indian Law (New York: Clearwater, 1977).

13. Ross, "Using the Congressional Serial Set," 208; Congressional Information Service, CIS US Serial Set Index (Washington, DC: Congressional Information Service, 1975-1998).
14. United States Government Printing Office, U.S. Congressional Serial Set, accessed July 2, 2014, www.gpo.gov/help/u.s. congressional_serial_set.htm

15. "Titanic" Disaster: Hearings before a Subcommittee of the Committee on Commerce, United States Senate (Washington, DC: Government Printing Office, 1912).

16. Tom Kuntz and William Alden Smith, The Titanic Disaster Hearings: The Official Transcripts of the 1912 Senate Investigation (New York: Pocket Books, 1998).

17. Tom Kuntz, The Titanic Disaster Hearings: The Official Transcripts of the 1912 Senate Investigation (Los Angeles: New Star Media, 1998).

\section{Appendix 1. Purdue University's Cataloging Template for Brief Records}

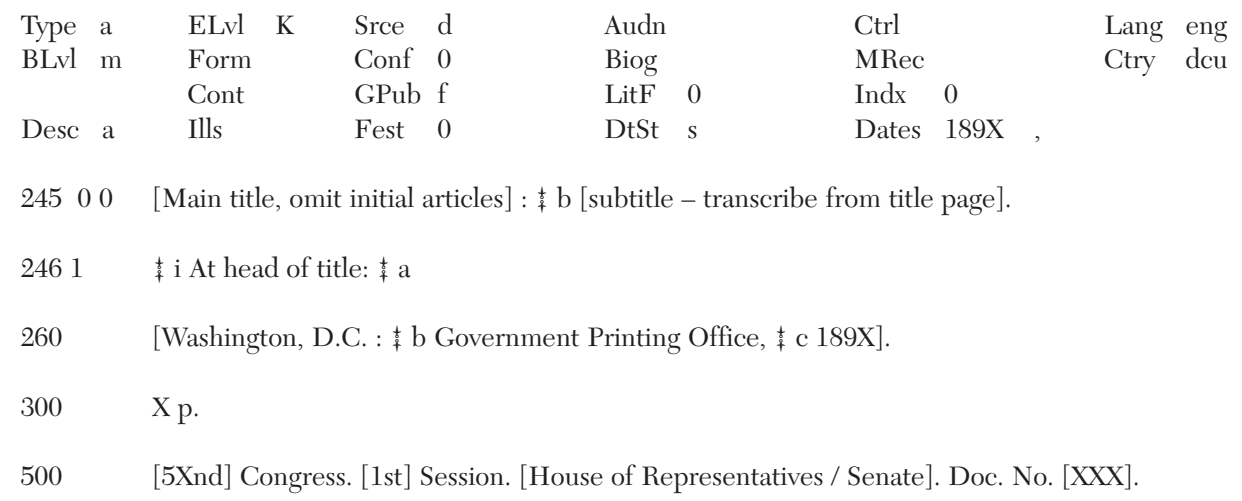

24500 [Main title, omit initial articles] : $+\mathrm{b}$ [subtitle - transcribe from title page].

$2461 \quad++$ i At head of title: $\begin{gathered}+ \\ +\end{gathered}$

260 [Washington, D.C. : 市 b Government Printing Office, 虽 c 189X].

$300 \quad \mathrm{X}$ p.

[5Xnd] Congress. [1st] Session. [House of Representatives / Senate]. Doc. No. [XXX].

\section{Appendix 2. Example of Full-level Bibliographic Record for a Congressional Serial Set Document}

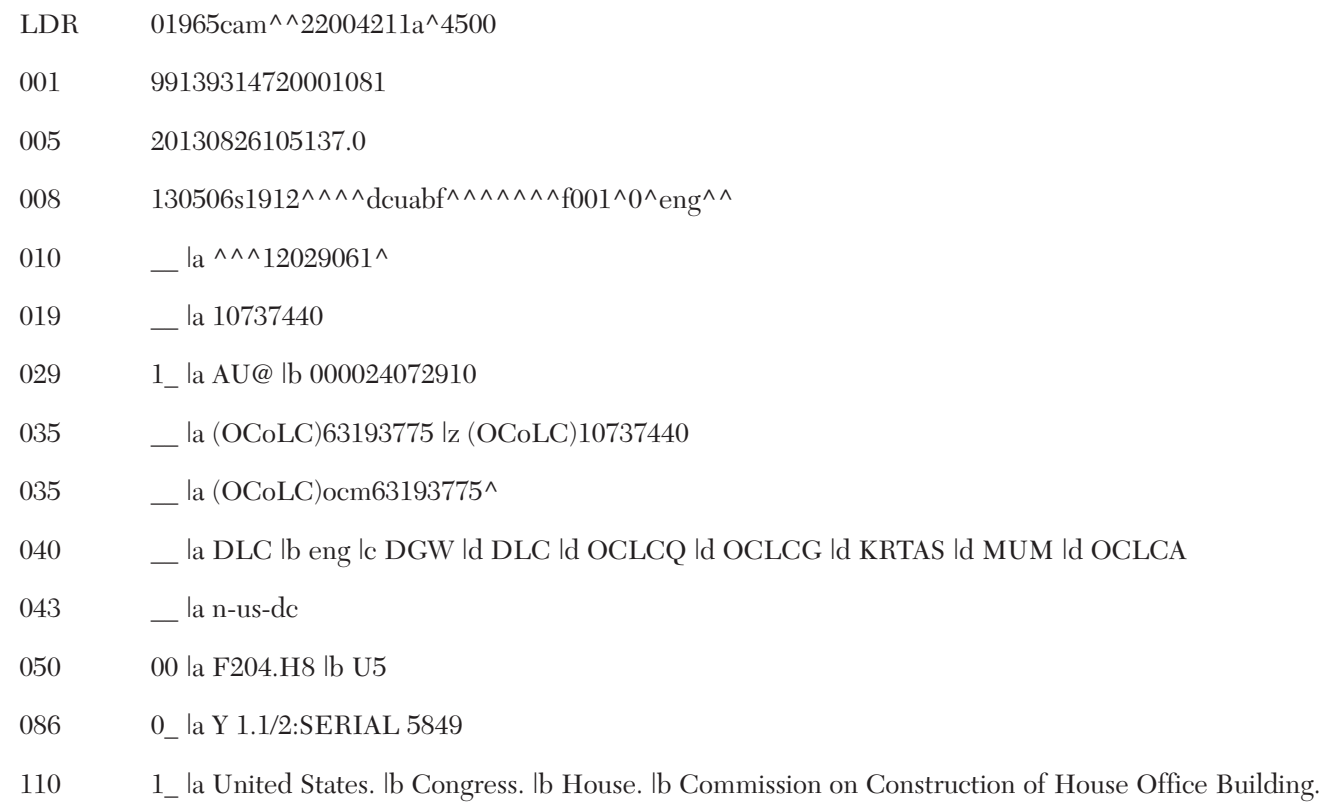




\section{Appendix 3. Example of Brief Record with Minimal Cataloging for a Document from the Congressional Serial Set (Purdue University).}

10 la Report of the Commission to Direct and Supervise the Construction of the House Office Building.

_ la Washington : lb G.P.O., lc 1912.

_ la vi, 265 p., [85] p. of plates : lb ill., map; lc $41 \mathrm{~cm}$.

1_la House report / 61st Congress, 3d session ; lv no. 2291

_ la Spine title: History House Office Building; running title: Report of the House Office Building Commission.

_ la A commission appointed under the Sundry civil appropriations act approved March 3, 1903.

_ la Commission members: Joseph Gurney Cannon, William Peters Hepburn, James Daniel Richardson.

_ la Includes index.

20 la Cannon House Office Building (Washington, D.C.)

_0 la Public buildings lz Washington (D.C.)

1_la Cannon, Joseph Gurney, ld 1836-1926.

1_la Hepburn, lc Mr. lq (William Peters), ld 1833-1916.

1_ la Richardson, James D. lq (James Daniel), ld 1843-1914.

0_ la Report of the House Office Building Commission.

1_la United States. Ib Congress. Ib House. It Report ; Iv 61st Congress, no. 2291.

_0 la United States congressional serial set ; lv serial no. 5849 .

\footnotetext{
LDR 00908cam a2200133K 4500

$001 \quad 99141994450001081$

$005 \quad 20130819084354.0$

$008 \quad 130506$ s1892 dcu f000 0 eng d

$035 \_$la (InLP)2826847-wlafdb-Voyager

24500 la Letter from the Acting Secretary of the Treasury : Ib transmitting a copy of a letter from the Second Comptroller recommending the insertion in the sundry civil bill for the fiscal year ending June 30, 1893, of a proviso in connection with the appropriation for the construction of buildings at, and the enlargement of, such military posts as, in the judgement of the Secretary of War, may be necessary. January 28, 1892 - referred to the Committee on Appropriations and ordered to be printed.

1_ li At head of title: la Buildings at Military Posts

$260 \ldots$ _la [Washington, D.C. : Ib Government Printing Office, lc 1892]

300

— la 2 p.

500

_ la 52d Congress, 1st Session. Ex. Doc. No. 105.
} 


\section{Appendix 4. Example of a Record for a Document from the Project as It Appears in HathiTrust}

\begin{tabular}{|c|c|}
\hline \multicolumn{2}{|c|}{$\begin{array}{l}\text { Pension appropriation bill : report (to accompany H. R. } \\
\text { 10345). }\end{array}$} \\
\hline Corporate Author: & United States. \\
\hline Language(s): & English \\
\hline Published: & [Washington : G.P.O., 1893] \\
\hline Subjects: & $\begin{array}{l}\text { United States }>\text { Pension Bureau }>\text { Appropriations and expenditures } \\
\text { Military pensions }>\text { United States. } \\
\text { United States }>\text { Appropriations and expenditures. } 1894 .\end{array}$ \\
\hline Note: & $\begin{array}{l}\text { Submitted by the Committee on Appropriations, U.S. House of } \\
\text { Representatives. } \\
\text { "January } 27,1893 . " \\
\text { Caption title. }\end{array}$ \\
\hline Physical Description: & $31 \mathrm{p} . ; 24 \mathrm{~cm}$ \\
\hline Locate a Print Version: & Find in a library \\
\hline \multicolumn{2}{|l|}{ Viewability: } \\
\hline 目 Full view & nal from Purdue University) \\
\hline
\end{tabular}

\section{Appendix 5. Project Statistics}

- The project covered the period of June 2011-August 2012 (fourteen months).

- Purdue staff processed 110 physical volumes of the Congressional Serial Set.

- The volumes contained 30,410 individual documents for an average of 276 documents per volume (actual document count per volume varied widely).

- Staff found 10,284 records (about 33 percent) for individual documents already in WorldCat; most of these were records created by the staff at the University of Iowa as their contribution to the project.

- Purdue staff created 20,126 new brief records.

- Purdue library employees spent a grand total of about 2,450 hours on the project.

- The Purdue cataloging supervisor estimates that she spent 150 hours setting up the workflow and handling supervisory tasks; other staff contributed a total of almost 500 hours.

- About 1,800 student hours (30 hours a week) were spent on the project; most of the student time was devoted to record creation.

- The cataloging supervisor estimates that students averaged 3.5 minutes to create each record.

- Even with 650 hours of staff time included, Purdue employees spent less than five minutes per record/document processed. 